\title{
Poesia-ideograma: a lua móbile de Li Bai reimaginada por Haroldo de Campos
}

\author{
Diana Junkes Bueno Martha ${ }^{1}$ \\ A poesia encerra verdades primeiras cujo sentido pode \\ ser descoberto e compreendido pela tradução (Ungaretti) ${ }^{2}$
}

\begin{abstract}
Resumo: O objetivo do presente artigo é tecer algumas considerações sobre as traduções da poesia chinesa por Haroldo de Campos. Ao final do artigo, propõe-se uma leitura para uma tradução de um poema de Li Bai (Li Po) (701-762 d.C.). Incansável leitor da tradição e eximio tradutor, o poeta paulista erigiu uma obra constelar em torno de várias culturas a partir do estabelecimento de diálogos entre textos e contextos, sobretudo por meio de um trabalho tradutório ao qual ele deu o nome geral de transcriação, tendo nomeado, particularmente, de reimaginações, as traducões da poesia oriental. É por meio desse trabalho transcriativo que ele contemporanizou poetas de tempos e espaços diversos. Se de um lado a situação contemporânea, pós-utópica, aponta para uma crítica do futuro, dos paraísos prometidos, a poética da transcriação, em Haroldo de Campos, sustenta-se, ainda, como um alicerce para o ressurgimento de uma utopia da escritura que reúna povos e lugares em tempos de globalização. Sob essa perspectiva, apontar caminhos para a leitura das reimaginações da poética chinesa empreendidas por Campos parece um meio de dar destaque aos intercâmbios entre as culturas de língua portuguesa e a China, esta última compreendida, nos dias atuais, como um potencial econômico e como um desafio politico às relações internacionais, mas ainda à espera de uma leitura poética de sua realidade e lingua que o Ocidente possa empreender. O trabalho de Haroldo é, pois, uma homenagem à China e uma provocação ao leitor de língua portuguesa.
\end{abstract}

Palavras-chave: Li Bai; Haroldo de Campos; poesia chinesa; tradução; poética sincrônica.

\footnotetext{
1 Para citações bibliográficas ver também Diana Junkes Bueno Martha-Toneto.

2 In: BERNARDINI, A. F. Giuseppe Ungaretti e a tradução de Serguei Essiênin in WATAGHIN, L. (org.). Ungaretti daquela estrela à outra. Ateliê Editorial: São Paulo, 2003, p. 212.
} 


\section{Transcriar e reimaginar: a tradução para Haroldo de Campos}

Quando o poeta escreve sua poesia, está traduzindo em signos verbais sentimentos, imagens, ações, símbolos, sonhos. A revolução da poesia (ou a violência sobre a linguagem que ela opera) está não apenas no conteúdo que revela, mas na forma pela qual este conteúdo é revelado por meio da tradução que o poeta faz do mundo. Nesse espectro, a tradução de poesia de um para outro idioma é uma operação complexa, cheia de desafios, porque busca a re-velação do que é velado por meio da palavra poética, daí Novalis dizer que o tradutor "é o poeta do poeta" (apud CAMPOS, 1997, p. 269). Já Octavio Paz (1990) em seu belíssimo ensaio intitulado Traduccion: Literatura e literaridad diz que:

O ponto de partida do tradutor não é a linguagem em movimento do poema, mas a linguagem fixa do poema, sua operação é de certa forma inversa a do poeta: não se trata de construir com signos móveis um texto imóvel, mas desmontar os elementos desse texto, por de novo em circulação e devolvê-los à linguagem. Por isso a tradução poética é dinâmica. (PAZ, op. cit. p. 21)

Esse dinamismo não é peculiar apenas à tradução, a menos que se a considere, como sugere Paz, algo muito mais amplo do que a operação de passar um texto de uma língua para outra; ao escrever seu poema, o poeta traduz sua experiência de vida, sua poética, traduz suas próprias traduções; por isso a poesia é rara e por isso é tão difícil recriá-la, traduzi-la. Ela própria já é a tradução de um universo linguístico e humano; ela é fruto de um trabalho de lapidação da palavra bruta, porque a palavra, mesmo bruta, já guarda em essência toda a sua poeticidade.

Para muitos teóricos, a tradução não é uma técnica a ser dominada por critérios científicos, que imporiam ao tradutor uma obrigação de fidelidade; o que está em jogo na tradução é algo que vai muito além; é uma operação dupla entre o texto de partida e o texto de chegada, um jogo que não terá vitoriosos, mas se sustentará na sua tensão, porque a tradução jamais se igualará (e nem deve ser esta a intenção) ao original, pelo contrário, um double bind os manterá ligados.

A isso se acrescenta o fato de a tradução ser uma operação intervalar; o traduzir não diz respeito nem ao original nem ao traduzido, mas se concretiza ao tomar emprestado ora do texto-cultura de origem, ora do texto-cultura de chegada aspectos, signos, significados e significantes (LARANJEIRA, 2003). Há, portanto, uma constante tensão, um ir e vir, sem origem definida; o trabalho do tradutor constitui-se, pois, em eterno desconstruir, já que as possibilidades de reproposição dos signos do poema original são múltiplas, constantes invenções, reinvenções. 
Derrida (2002, p. 10) diz, em Torres de Babel, que a "tradução é uma transformação regulada de uma língua em outra - metáfora da desconstrução". Inevitavelmente, a tradução leva as marcas de quem a executa, sujeito social e histórico, e deve considerar vários níveis de leitura, conforme aponta Laranjeira (2003): o semântico, o linguístico-estrutural, ou seja, reiterações fonéticas e sintáticas, agramaticalidades, recuperando e compensando possíveis perdas do trajeto. A tradução, por conseguinte, é um ato criativo que aponta para a indecidibilidade, há uma perda das marcas originais uma vez que o texto traduzido trará re-marcas, des-marcas, que asseguram as duas existências, sem a redução de identidades preconcebidas. A meu ver, o trabalho de Haroldo de Campos funda-se grandemente nessa perspectiva tradutória.

O percurso feito pelo poeta foi norteado por uma busca: a busca da invenção. Para ele, a novidade e a redescoberta da tradição viriam, também, por meio da tradução e da incorporação de um universo traduzido, levando em conta o caráter de patrimônio cultural da humanidade que se pode atribuir à literatura e considerando a tradução como instância da crítica. Ou seja, para Haroldo de Campos, toda operação tradutória é necessariamente uma operação crítica na medida em que é preciso compreender criticamente o universo do poema traduzido.

A esse processo tradutor, Haroldo de Campos chamou transcriação (CAMPOS, 1992), uma vez que, de acordo com sua concepção, na poesia a aproximação sonora é aproximação semântica e a aproximação semântica na tradução só se configura quando as figuras e os efeitos paronomásticos (que podem também ser figurativos) tornam-se transfiguras. Quando são transcriados, os poemas tornam-se acessíveis, há uma nova possibilidade de contemplação. Verter textos criativos é, ao mesmo tempo, um exercício de crítica e criação paralela, autônoma e recíproca, concomitantemente. Assim sendo, traduzir poesia é, antes de qualquer coisa, perceber o dominante poético do texto de origem e recriá-lo na língua-cultura de chegada e isso inclui não apenas a tradução dos significados, mas, fundamentalmente, dos significantes.

Outro aspecto a ser mencionado é que a tradução como crítica, como transcriação, coloca em diálogo distintos poetas, a partir da consideração da materialidade da palavra poética que permite, como disse Haroldo:

[...] encarar a poesia, transtemporalmente, como um processo global e aberto à concreção sígnica, atualizado de várias épocas da história literária e nas várias ocasiões materializáveis da linguagem (das linguagens). Safo e Bashô, Dante e Camões [...] Celan, Góngora e Mallarmé são, para mim, nessa acepção fundamental, poetas concretos [...]. O tradutor, como diz 
Novalis, "é o poeta do poeta", o poeta da poesia. A tradução - vista como prática de leitura reflexiva da tradição - permite recombinar a pluralidade dos passados possíveis e presentificá-la, como diferença, na unidade bic et nunc do poema pós-utópico. (CAMPOS, 1997, p. 269).

A tradução, nesse sentido, passa a atender, ao longo dos anos, ao projeto haroldiano do poema do poema pós-utópico, "crítico do futuro e de seus paraísos sistemáticos" (CAMPOS, 1997, p. 269), que contemporaniza culturas. O exercício transcriativo ingressará mais e mais intensamente na construção dos poemas de autoria do próprio poeta em seus últimos anos de vida, de modo que a ideia de transculturação torna-se uma das égides fundamentais para a compreensão de poemas como A Máquina do Mundo Repensada (CAMPOS, 2000). Naturalmente, tal processo sempre existiu na obra haroldiana, mas é visível o aprofundamento do papel da tradução nos últimos projetos (TONETO, 2008 a, b; 2011).

O Haroldo de Campos tradutor está muito presente em A Máquina do Mundo Repensada, não apenas por utilizar suas traduções, mas porque, como devoração crítica e antropofágica dos textos que traduziu, incorpora-os ao poema, como um modo de criar seus precursores (BORGES, 1979). Ou seja, as possibilidades de reproposição dos signos dos originais são maximizadas porque o poeta, para além da transcriação, passa a uma supratranscriação: metalinguisticamente parece transcriar o que já havia transcriado. É nesse sentido que se pode fazer uso da expressão transhuciferar, que cabe não apenas para a tradução que Haroldo fez da Comédia, mas qualquer outra tradução:

A partir da explosão de luz no Paraíso, a tradução de Haroldo oferece uma possibilidade de inversão radical, um efeito da operação de tradução como caminho iluminador. A culpa de Lúcifer, segundo a leitura de Haroldo, foi il traspassar del segno, ultrapassar o limite, o signo. A tradução sugere uma superação do texto original, sendo uma "empresa luciferina". Ela aponta para uma leitura retrocessiva do Inferno, agora como inverso simétrico da metáfora da luz. (LOMBARDI in: CAMPOS, 1998, p. 12, grifos do autor).

Em A Máquina do Mundo Repensada, a sensação que se tem é de que, a cada verso, o poeta ultrapassa o signo; seu processo criativo é, como as traduções que faz, uma empresa luciferina ou desbabelizante. Em meados dos anos de 1970, Haroldo de Campos (1976, p. 39) já ressaltava que:

Na tradução de poesia vige a lei da compensação: vale dizer, onde um efeito não pode ser exatamente obtido pelo tradutor em seu idioma, cumpre-lhe compensá-lo com outro, no lugar onde couber [...]. 
A tradução é, pois, suplementar, integra o original e joga, em termos derridianos, o jogo da diferença. Conforme aponta Siscar:

[...] a desconstrução é um gesto produtor de sentido, mas uma produção que tem como particularidade a ativação ou a aceleração do movimento conflitante no qual o próprio texto e sua leitura estão implicados. A esse movimento, Derrida preferiria mais tarde dar o nome de duplo gesto ou duble bind, usando a expressão inglesa. A desconstrução interpreta o texto como um duble bind no qual está em jogo a própria impossibilidade de sentido (SISCAR, 2003, p. 153).

Sob esse prisma, é uma substituição (recriação) de significantes que não se apagam frente aos significantes do original, mas que se mantêm latentes em corpo linguístico diverso, amalgamando poeticamente poetas e culturas. Um corpo verbal não se deixa traduzir ou transportar para outra língua; o corpo traduzido não é transportado pela tradução, mas reinstituído. $O$ tradutor procura justamente a corporalidade da escritura para que possa levar a bom termo essa operação que lida com o fato de leitura e escrita não coincidirem e com o fato de que a escritura nada mais é que um rastro. Como aponta Nascimento:

Não se pode dizer que escrita e leitura co-incidam, pois não existe um ponto absoluto que faça incidir uma sobre a outra [...] uma suplementa a outra: apenas se pode ler o que em algum momento foi escrito, e somente se pode escrever porque de algum modo se foi treinado para leitura [por isso] [...] o signo é coisa que se inscreve, rastro escrito de um aparelho nem finito, nem infinito, indecidível [ ]. Enquanto jogo permanente do indecidível, o movimento supletivo do rastro faz com que um traço possa de novo retornar, porém na diferença. (NASCIMENTO, 1999, p. 173-187).

É por essa razão, inclusive, que a motivação da tradução de poesia deve levar em conta o caráter isomórfico do texto poético, daí a necessidade de transcriação, pois esta leva a semelhança onde antes havia diferença; desbabeliza textos e faz convergir poeticamente universos distintos. A convergência é ainda mais acentuada, no trabalho de Haroldo de Campos, por sua dedicação a línguas como o hebraico, o aramaico, o japonês e o chinês. No caso dos dois últimos, por meio desse movimento de tradução como criação e como crítica, Haroldo coloca em diálogo Oriente e Ocidente. Vejamos, pois, alguns aspectos dessa aproximação poética. 


\section{2. "Providenciar visões do impossível": a poesia chinesa em português}

Há uma característica fundamental que movimenta a tradução na prática haroldiana, e que é, como apontado, a busca pela invenção, pela novidade. Assim, pode-se destacar duas linhas de força que conduzem o trabalho do poeta: o estabelecimento de um paideuma e o manejo deste por meio da articulação do que Haroldo de Campos definiu como poética sincrônica. Segundo ele, a leitura sincrônica da tradição corresponde a uma postura poética engajada que se volta para a leitura do passado em função do presente (CAMPOS, 1997). Essa ideia alia tanto o conceito de poética sincrônica de Jakobson, quanto o Jetžeit benjaminiano e se torna um mecanismo de renovação porque está alicerçada ao "make it new" poundiano, cujos preceitos orientam a escolha do paideuma (POUND, 1970). Como sublinharam vários críticos, Haroldo radicaliza Pound (MEDEIROS, 2010, [s. p.]) ao tornar sua própria perspectiva de abordagem do cânone mais dialógica, mais plural (DANIEL, 2005; SANTAELLA, 2005; YUN, 2010).

Um dos pontos de apoio desse dialogismo caleidoscópico é sem dúvida articulado pelas incursões do poeta pela poesia oriental; incursões estas que renderam trabalhos como Yugen: caderno japonês (1988); Hagoromo de Zeami (2003); Escrito sobre Jade (2009), além de diversos textos críticos sobre as poesias e culturas chinesa e japonesa. Várias são as razões pelas quais um inventor e poeta do calibre de Haroldo Campos mergulham em textos como esses. A própria ligação com Pound marcada, inclusive, por troca de correspondências, pode ter contribuído para o interesse particular de Haroldo pelos textos orientais, sobretudo chineses ${ }^{3}$.

A trajetória epistolar entre os irmãos Campos, Décio Pignatari e Pound foi extremamente profícua para o Movimento da Poesia Concreta e as leituras que o poeta americano tinha de Fenollosa (1853-1908), importante estudioso da cultura oriental, foram decisivas para inspirar, por sua vez, os poetas paulistas, leitores de Pound, aspecto que se vê no tratamento ideogramático que receberam muitos poemas concretos, marcados pela condensação/concisão da forma e pelo aspecto verbivocovisual (CAMPOS, et al, 2010). Segundo Haroldo de Campos, os estudos de Fenollosa, sobretudo The Chinese Written Character, compilados por Mary Fenollosa, acabaram por entrar na circulação sanguínea da poesia contemporânea (CAMPOS, 2000, p. 26), uma vez que pela via dos ideogramas a função poética parece maximizar-se:

3 Parte dessa correspondência pôde ser por mim consultada no acervo de Ezra Pound, na Biblioteca Beinecke da Universidade de Yale (setembro/2012). 
[...] Em poesia - adverte Jakobson - toda coincidência fonológica é sentida como um parentesco semântico [...] O que o exemplo chinês encarecia para Fenollosa era a virtude homológica e homologadora da função poética. Poesia em caracteres escritos, a poesia chinesa permitia ao estudioso norte-americano explorar (inspecionar) essas "homologias" na pauta visual, na dimensão grafemática [...]. (CAMPOS, 200, p. 48, grifos do autor).

E são esses aspectos que Pound e seu imagismo devorarão de Fenollosa. Ressalta Haroldo:

Pound (inspirado em Fenollosa) quer manter vivo e ativo o circuito na língua inglesa, enquanto poeta: guardar, na abstração simbólica, a tensão para a concretude sensível; preservar, na linguagem verbal, tanto quanto possível, aquela propriedade dos ícones de despertar, no espírito, "sensações análogas àquilo que se parecem” (Ibid, p. 95, destaques do autor).

Percebe-se, portanto, que é significativo o olhar que Campos devota à poesia chinesa, à medida que este vincula-se também, como colocaria Jorge Luís Borges (1979), a certo modo de criação do precursor Pound e de suas idiossincrasias a partir do universo oriental, sobretudo chinês.

Há ainda outro aspecto sobre a ligação de Haroldo de Campos à poesia chinesa que gostaria de ressaltar. Tenho afirmado em mais de um artigo que há um movimento duplamente utópico em Haroldo de Campos; um marcado pela utopia de vanguarda; outro que chamo de utopia fáustica (TONETO, 2011).

Segundo essa perspectiva, o segundo modo utópico apontado diz respeito a um desejo implacável de retorno às origens, aos grandes textos do cânone; trata-se, a meu ver, de uma empresa fáustica de busca do conhecimento de diferentes culturas por meio da tradução/ transcriação de textos poéticos que vão desde fragmentos bíblicos, textos clássicos, como gregos e latinos, passam pelos poemas orientais, visitam os poetas russos e outros tantos alemães, holandeses, ingleses, franceses, espanhóis etc. Esse movimento leva Haroldo, em especial nos últimos anos de vida, a um amplo e significativo projeto de traduções e reimaginações. Entretanto, a dupla via utópica, da maneira como a percebo, é fundante e engendra o seu projeto desde os primeiros anos: ainda que se torne mais contundente ao final da vida do poeta, essa utopia fáustica parece ter sempre motivado o seu projeto poético. Isso explica que o infatigável poeta-leitor tenha se dedicado a escrever sobre poesia chinesa já desde meados dos anos 1960, pelo menos.

Em $A$ arte no horizonte do provável, de 1977, Haroldo reúne textos escritos em anos anteriores, entre eles "A quadratura do círculo", em que discute reimagi- 
nações (já a essa época propunha esse termo para as traduções de poesia chinesa dada a impossibilidade de criação dos ideogramas numa língua não tonal como o português) de cinco odes chinesas, anteriormente traduzidas para o inglês por outros poetas, entre os quais, Ezra Pound. Nesse texto, um verdadeiro 'caderno de campo', Haroldo de Campos (1977, p. 122) define seu método de trabalho: “[...] exame do texto original, com auxílio de uma versão intermediária (literal ou não); estudo dos principais ideogramas segundo o método poundiano [...]". No caso das odes mencionadas, os objetivos principais das traduções foram: (i) valorização do aspecto visual da tradução dos poemas ideográficos; (ii) esforço para manutenção da síntese e da concisão de uma linguagem regida pela analogia; e (iii) tentativa de recriação dos efeitos paralelísticos e os efeitos de correspondência léxica.

Além disso, em profusão prismática de influências, em tais reimaginações, Haroldo deixou-se inspirar pela poesia medieval portuguesa e acrescentou epígrafes aos poemas, a exemplo de outros tradutores, inclusive Pound, sem desprezar a importância da intuição nas traduções, entendida aqui como sensibilidade para captar a função poética do original e dar-lhe novas possibilidades linguísticas em português (CAMPOS, 1977, p. 122-123).

Em A Operação do Texto, de 1976, Haroldo de Campos ressalta aspectos da poesia de Li Shangyin (812-858 d.C.), poeta da dinastia Tang (fase tardia), no ensaio "Uma arquitextura do barroco". Aqui Campos recupera um "espírito barroco", na história literária, sublinhando uma dicção gongorina tanto nos gregos antigos quanto no chinês Li Shangyin, bem como em Mallármé, Lezama Lima e outros, daí o título arquitextura do barroco. No caso do poeta chinês, o contexto em que ele se inseria, conforme aponta Haroldo de Campos, era de tensões entre perspectivas de mundo aparentemente irreconciliáveis, daí que isso se refletisse, barrocamente como quer Haroldo, em sua poesia, para expressar a divisão subjetiva entre puritanismo confuciano e o ascetismo budista; hedonismo sibarita e imortalidade taoísta. Do ponto de vista formal, a poesia de Li Shangyin é repleta de imagens cultistas e de um conceptismo avant la lettre, como se nota nos jogos especulares entre ideogramas; jogos estes que o poeta de campos e espaços flagra também em Poe, como exposto no ensaio "Texto-Espelho (Poe, Engenheiro às avessas)", presente no mesmo livro.

O mesmo Li Shangyin é recuperado em outro instigante texto haroldiano. Trata-se de Barrocolúdio: Transa Cbim, publicado pela primeira vez em 1988 e republicado no Segundo Arco Íris Branco, obra póstuma de 2010. Nesse ensaio, a ousadia haroldiana põe em diálogo Lacan e o poeta chinês, não sem deixar de notar neste último os "revérberos sutis da alquimia mallarmaica" (CAMPOS, 2010, p. 226). O que Haroldo aponta não é simplesmente o barroquismo de Li 
Shangyin, cujas traduções/reimaginações de alguns poemas comenta ao longo do texto, mas, sobretudo, destaca a constelação de significantes, a barroquização destes nos poemas e é aí, em festa constelar, que Lacan é convocado para dar ver o gozo dessa transa chim:

Assim, na rutilância estelar de suas representações em cascata, barroquiza-se o nosso Li. E caligraficamente responde um "sim" à provocativa pergunta do Mestre La (K'an). Gozo chim? Por que não? Sim. Se não (CAMPOS, 2010, p. 226).

O comentário acima é um dentre os vários exemplos que se pode convocar para mostrar o alcance das reflexões fáusticas empreendidas por Haroldo de Campos, as quais engendram uma "vivissecção implacável" do universo traduzido (CAMPOS, 2005), fazendo convergir tempos e espaços em um projeto poético que tem 'razões antropofágicas que a própria razão desconhece', porque movido por uma pulsão absolutamente visceral de re-inventar o cânone, de fazê-lo desbabelizar-se para falar português brasileiro.

Apesar de todas essas incursões no universo chinês, talvez seja em Arco-Íris Branco (1997) que Haroldo de Campos melhor formule a dificuldade que a tarefa de reimaginar a poesia chinesa impõe, mais especificamente no ensaio Três Versões do Impossível: Wang Wei. Ao discutir os recursos e escolhas feitas no trabalho de tradução de poemas desse poeta, Haroldo diz:

Traduzir poesia chinesa já foi visto como tentativa de empreender a quadratura do círculo. Ad impossibilita nemo tenetur. Ninguém é obrigado a fazer coisas impossíveis. O tradutor (transcriador) de poesia é. Providenciar versões do impossível, afinal, não constitui o sentido mais essencial de sua tarefa? (CAMPOS, 1997, p. 182, grifos do autor).

Sobre algumas possíveis versões do impossível nos debruçaremos na seção seguinte, mas antes é preciso pontuar, ainda, um elemento crucial a respeito da tradução/reimaginação da poesia chinesa por Haroldo de Campos: o poema móbile. Mais uma vez, fazendo convergir tempos e espaços, o poeta paulista aproxima artistas-escritores distantes no tempo. Para traduzir Wang Wei, vale-se dos móbiles leves de Calder, pois aproveita a disposição espacial dos móbiles a fim de criar, na folha em branco e sob as rasuras do original, um móbile poético; replicando a visualidade do ideograma, atentando sempre para as compensações sonoras. O diálogo com a harmonia das formas de Calder bem demonstra o trabalho poético-visual-ideogrâmico de Campos, marcando-o com o que Italo Calvino 
(1988) denominaria, em Seis Propostas para o Próximo Milênio, de "Leveza”. Leveza que harmoniza a poesia chinesa no espaço branco da página.

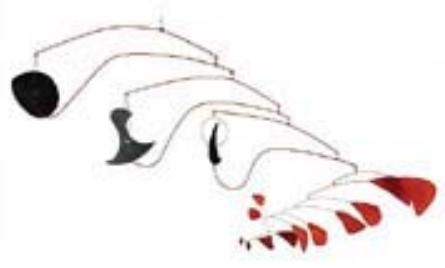

Red Gongs. Alexander Calder, 1950/ Alumínio, fios de aço, bronze e arame. Fonte: Metropolitam Museum of Art. http://www.metmuseum.org/collections/search-the-collections/210009085

De todos os poemas móbiles reimaginados por Haroldo de Campos, aqueles da coletânea Escrito sobre Jade (1996; 2009) são os que, de fato, causam-nos maior impacto. Muitos já haviam sido publicados em outros momentos, mas a sua reunião em um único volume torna-os mais do que reimaginações, faz deles um grande ideograma do pensamento poético de Haroldo que o nome plural da coletânea, fruto do amálgama entre Le livre jade de Judith Gautier (1908) e Escrito sobre um corpo, de Severo Sarduy (1969), retrata perfeitamente.

Dentre todos os poemas, os de Li Bai chamam a atenção pela elevada poeticidade e pelos recursos empregados por Haroldo nas reimaginações (MEDEIROS, 2010). Vejamos, então, a título de ilustração do que se vem dizendo até aqui, um deles sob uma perspectiva de análise não da poesia chinesa, mas de sua chegada ao português e do diálogo transcultural estabelecido por Haroldo.

\section{Poema-Ideograma: a lua móbile de Li Bai}

Li Bai é um importantíssimo poeta que viveu entre 701-762 dC, também chamado de "O Imortal Exilado de sua Terra". Considerado um dos maiores poetas da China, ele teve uma vida desregrada, marcada pela excentricidade e boemia e morreu bêbado, afogado em um lago, tentando apanhar a lua (CAMPOS, 2009) ${ }^{4}$. Essa lua inatingível parece povoar os seus poemas e é dela, sobretudo, que se

4 Para interessante resenha de dados biográficos de Li Bai, cf. MEDEIROS, Sérgio. Li Bai e Mao T’se Tung em Português. Resenha. In: Sibila: Revista de Poesia e Cultura. 23, jun.2010. Disponível em: http:/ / sibila.com.br/mapa-da-lingua/li-bai-e-mao-tse-tung-em-portugues/3792. Acesso: 09/01/2013. 
falará brevemente a seguir, tomando como pedra angular uma das reimaginações haroldianas para a obsessão lunar de Li Bai.

\section{Sob a lua, nuvens são cambraias ${ }^{5}$}

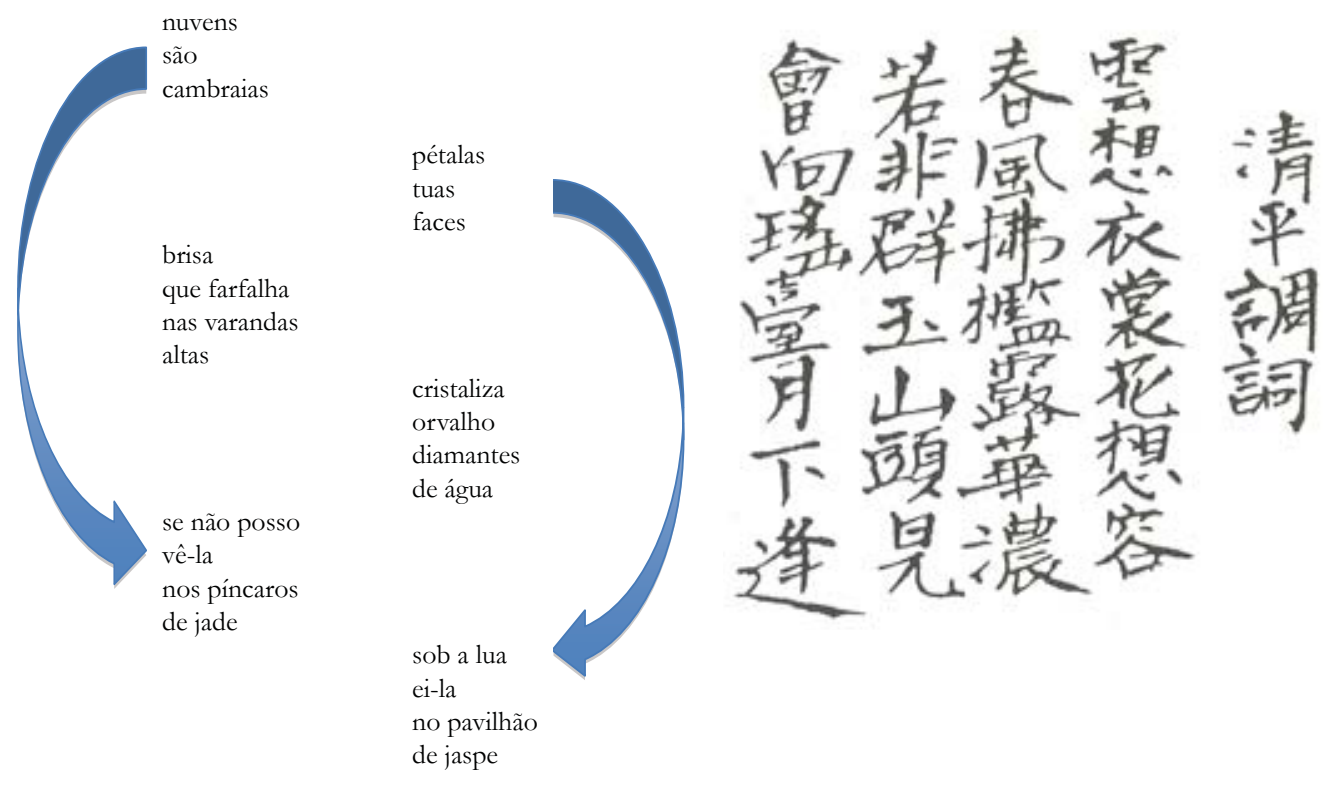

(CAMPOS, 2009, p. 57)

Chama a atenção, em primeiro lugar, o caráter de permutabilidade das estrofes, que garante múltiplas ordenações da leitura: (i) a leitura na ordem em que aparecem as estrofes; (ii) a leitura das estrofes ímpares e depois das pares ou vice-versa; (iii) a leitura da última para a primeira estrofe e, ainda, (iv) a leitura por diferentes leitores, como se fosse um poema para ser lido como diálogo. Esse aspecto dá força de ideograma ao poema reimaginado por Campos e as leituras em ordem inversa acabam por reproduzir também a ordem natural da leitura da escrita chinesa. Considerando uma abordagem das estrofes pela ordem em que surgem, é possível captar vários aspectos; estes podem valer ou não para as outras ordenações.

5 A exacerbação deste diálogo pode ser apreciada pela improvisação entre Haroldo de Campos e Madan, que musicou a tradução. Disponível em: http://www.youtube.com/watch?v=Tc7-JF39_ls \&noredirect=1 
Os primeiros versos marcam a leveza do texto: nuvens/são/cambraias; e surgem com forte carga metafórica pela aproximação entre nuvens e cambraias A cambraia é um tecido leve, de algodão ou linho, usado em rendas e bordados, portanto, aqui dois pontos merecem destaque, não apenas a leveza e a sutileza poética da comparação, mas o fato de o tecido ser usado para rendas e bordados, portanto, como matéria-prima para a criação da leveza. Na segunda estrofe, mais uma vez, a metáfora "ideogrâmica" (ou, arriscando o neologismo, ideorgânica) presentifica-se pela aproximação entre pétalas e faces. A sonoridade em /u/ de nuvens reverbera em tuas; a sibilação, que já havia surgido na primeira estrofe e que percorrerá todo o poema, se repete em pétalaS e faCeS, emprestando suavidade à expressão da amada. Vale notar aqui também que há como que um deslocamento do olhar do eu-lírico, em sentido de verticalidade, estabelecendo analogias para céu, nuvens, faces da amada.

Em seguida, na terceira estrofe, as faces são equiparadas à brisa farfalhante e o campo semântico do tecido, da cambraia, é retomado por farfalhar, amarrando, como em um ideograma, a imagem sutil que unirá a amada aos elementos da natureza e à suavidade da cambraia. Farfalhar, portanto, liga-se ao barulho do tecido quando a pessoa que o veste se movimenta, mas também à leveza e à delicadeza dos movimentos da borboleta. Leveza e sutileza dão a tônica do poema e são, ao que tudo indica, as características mais fortes da amada, aquilo que a torna bela. No caso da terceira estrofe, as faces-brisa farfalham e a amada, já mais próxima do céu porque nas varandas altas, mostra-se inacessível.

Cambraias, faces, farfalha, altas rimam toantemente e ecoam em varandas; considere-se também a aliteração /f/ de faces e farfalha. Desse modo, os recursos paronomásticos garantem extrema concisão e contribuem, no plano imagético, para a aproximação reimaginativa entre o texto de origem e o de chegada, em uma operação que poderíamos chamar des-babelizante na medida em que se aproximam, por meio da poesia reimaginada, recursos linguísticos do chinês e do português.

$\mathrm{Na}$ quarta estrofe, água reproduz a assonância /a/ das estrofes anteriores, garantindo equilíbrio ao poema móbile que em suave farfalhar, pela disposição das estrofes, vai de um lado a outro. Brisa da estrofe anterior rima com cristaliza e ambas associadas a faces-pétalas sugerem que são lágrimas de brisa que correm pelo rosto da amada ${ }^{6}$. Mas há um porém aqui. Se lidas com mais atenção, as estrofes três e quatro podem indicar que a brisa cristaliza o orvalho e este torna-se diamante.

6 Considerando-se a leitura cuidadosa que Haroldo de Campos faz de Gregório de Mattos, é preciso notar que talvez haja, no poema em análise neste artigo, uma referência ao conhecido soneto de Gregório de Mattos Aos afetos e lágrimas derramados na ausência da dama a quem queria bem. (MATTOS, 2010). 
Diamantes podem indicar, então, as lágrimas dos amantes (e não apenas da amada) que não podem estar um com o outro; lágrimas-brisa da amada e lágrimas-orvalho do eu-lírico. As lágrimas da amada tornam-se o orvalho das lágrimas do eu-lírico e ao caírem na água, ambas, misturadas, tornam-se diamantes.

A quinta estrofe corrobora esse choro ou lamento, pois constata-se que o eu-lírico não pode ver a amada nos altos cumes (píncaros) de jade. Aqui a distância entre ambos, que fora assinalada por varandas altas, se intensifica na medida em que píncaros coloca-se como gradação para varandas, ou seja, em movimento crescente a amada passa das altas varandas para os pincaros de jade, e este, por seu caráter precioso e raro, torna ainda maior a distância entre a amada e o lugar de onde fala o eu-poético, como se este estivesse, talvez, impossibilitado de chegar a ela, já que parece ocupar posição inferior, ao menos espacialmente. Porém, a solução para o impasse entre desejar ver e não poder, que causa sofrimento a ambos, se admitirmos correta a hipótese das lágrimas, chega à última estrofe pela evocação da luz da lua no pavilhão de jaspe: sob a lua/ ei-la/ no pavilhão/de jaspe. O desenho da lua pode ser visto na diagramação do poema (veja-se as setas indicadas, cuja semi-circularidade remete também ao yin e ao yang).

A última estrofe recupera a sonoridade da segunda no que concerne ao /u/ em lua e também a lateral de pétalas que surge em lua e ei-la e que também estava presente na estrofe anterior em vê-la. JaSpe recupera a sibilação do início do poema e recoloca ideogramaticamente o esforço de concisão empreendido por Haroldo de Campos ${ }^{7}$, também perceptível na aliteração em /p/ que está em pétalas, pavilhão, jaspe, posso, pincaros. Por fim, destaque-se a rima e o parentesco sonoro mais bonitos entre o raro jade e o erótico vermelho jaspe.

Não se trata apenas de um poema em que a noite de luar surge ao final, mas talvez se possa dizer que é a amada quem "anoitece" no poema, que inicia leve entre nuvens que podem ganhar o atributo de cambraias suaves por estarem em frente à lua, e termina grave, extremamente poético e carregado pelo erotismo que a luz da lua e o jaspe engendram. Mas porque anoitece sob a lua, a amada, de fato, converte-se em alegria suprema. O vermelho do jaspe irrompe como se fosse uma aurora ao luar (não nos esqueçamos de notar que jaspe rima toantemente com faces e as faces podem ter cor de jaspe). É preciso pensar aqui em um pavilhão vermelho iluminado pela lua. Ver torna-se ter na gramática poética em ação no poema, garantindo que os ideogramas originais sejam, por meio da reimaginação proposta, recuperados à luz do esforço transcriativo que aproxima culturas e uni-

7 Cabe notar aqui que cada estrofe pode ser lida com um haicai. Este é outro possível diálogo a ser explorado, mas escapa ao objetivo deste trabalho empreender esforços no sentido de ampliar tal discussão. 
versos poéticos tão distantes pela materialidade dos significantes em português, pela concisão do texto, pela disposição gráfica do poema.

Retomando: O poeta ama platonicamente, mas seu amor pode tornar-se algo entre o platonismo e a posse. A lua e o pavilhão de jaspe surgem como revelação de uma cena só acessível a ele, como se pudesse ter o objeto de seu amor ao seu alcance em momento de contemplação secreta, um voyeur. É a lua que engendra a visão, sua luminosidade converterá o que era brisa, orvalho e diamante na mulher amada vista, em banho de luar, no pavilhão de jaspe. Tudo parece atuar como se a lua tornasse acessível o caminho dos amantes, como se apesar da distância entre ambos, ela os colocasse próximos ${ }^{8}$. A imagem é belíssima pois é o tenebroso afastamento imposto pela altitude dos píncaros de jade é subvertido pela lua a iluminar os pavilhões de jaspe.

Um leitor menos atento às artimanhas de Haroldo, talvez não perceba a presença parcial da lua em todo o poema (já destacada pelas setas apontadas acima), num jogo interessante de reiteração da sonoridade $A L e L A$, que está em pét $A L a s$, farf $A L h a$, crist $A L i q$ a, orv $A L b o$, e que surge espelhada em vê-LA, eiL $A$ e mostra-se exuberante em $L u A$. Poder-se-ia dizer o mesmo do $A S$ de jaspe, embora as recorrências sejam em menor número: cambrai $A S$, pétal $A S$, varand $A S$, alt $A S$ e, finalmente, $j A S p e$. Dessa forma, desde a segunda estrofe, um resquício de luar e de jaspe vai se impondo, percorrendo os versos, seus meandros, com sutileza e precisão, o que permite pensar na simultaneidade do que é flagrado nas estrofes, como se compusessem planos de uma visão que acontece em momento único que se mostra ao leitor prismaticamente, caleidoscopicamente. Trata-se da construção da imagem de uma mulher; da mulher amada, cujas faces de pétalas e de jaspe (talvez?) se iluminam sob o luar e atingem o olhar do amado.

Para ler Li Bai, Haroldo de Campos recupera as subdivisões prismáticas da ideia de Mallarmé (2002), mostrando que ambos podem ser um tanto quanto barrocos, mas, além disso, ressaltando que em poesia, a função poética dominante instaura um novo horizonte de possibilidades de leitura, em que a reproposição dos signos tende à infinitude mais do que à plenitude de uma leitura que se possa considerar acabada; mostra, ainda, que a disposição gráfica significa e que o aleatório tem pouco espaço na arte poética, ainda que um lance de dados não possa abolir o acaso.

Nessa perspectiva, um elemento intensifica a força do ideograma em foco: a metonímia, que percorre todo o texto e que viabiliza o deslizamento dos signi-

8 Aqui há uma ambiguidade. Pode-se pensar que a amada está junto do eu-lírico no pavilhão de jaspe (ei-la) ou que ele a vê de longe. De todo modo o que importa é o fato de ele estar olhando para ela. 
ficantes, em cadeia, ou em constelação (LACAN, 1998), como mostrou Haroldo de Campos no já citado Barrocolúdio: Transa Chim (2010). Há sempre um rastro, um objeto perdido, ou o próprio desejo do eu-lírico a girar na corporalidade da escritura, revelando, no caso deste poema de Li Bai, mais do que o amor, o desejo que se desloca, e que é parcialmente atendido pelo 'casamento' da lua com o pavilhão de jaspe e poder-se-ia pensar aqui na lua como a amada e no pavilhão como o amado.

Ao que tudo indica, a lua é um desencadeador de isotopias na poesia de Li Bai (conferir anexos ao final do artigo) e isso, provavelmente, acentua-se na reimaginação de Haroldo, porque este transforma sua tradução em palimpsesto, convocando versões e imaginários sobre a lua presentes na poesia ocidental. Dessa forma, o que se tem não é apenas a poesia de Li Bai, mas é a recepção da cultura chinesa por Haroldo de Campos, sua assimilação crítica e a homenagem ao grande poeta chinês não pela transcriação em si, mas porque esta o coloca em diálogo transtemporal com outros poetas, oriundos de outras culturas. Essas soluções não indicam apenas o trânsito entre culturas, mas a potência das reflexões de Haroldo em vários campos do conhecimento. Aqui, como para Li Shangyin vale a máxima haroldiana, já citada acima: "Gozo chim? Por que não? Sim. Se não" (CAMPOS, 2010, p. 226).

Sob a luz lunar da palavra-jaspe de Haroldo de Campos, erótica porque carregada de pulsão de vida, brota uma das mais profícuas (leves nuvens em cambraias, porém) formas de ultrapassar fronteiras: a poesia e sua transcriação. Quem sabe isso nos ensine, em tempos de aproximações culturais tão significativas, a providenciar o impossível para tornar a vida entre os diferentes e suas diferenças um poético esforço de possibilidades.

\section{Referências}

BERNARDINI, Aurora F. Giuseppe Ungaretti e a tradução de Serguei Essiênin In: WATAGHIN, L. (org.) Ungaretti daquela estrela à outra. São Paulo: Ateliê Editorial, 2003, pp. 212. BORGES, Jorge Luís. Kafka y sus precursores. In: - Prosa Completa. Buenos Aires: Bruguera, 1979, vol. 2, pp. 178-181.

CALDER, Alexander. Red Gongs. Nova York, 1950. Disponível para visualização em http://www.metmuseum.org/collections/search-the-collections/210009085. Data de acesso: 08/04/2013.

CAMPOS, Haroldo de. Barrocolúdio: Transa Chim. In: Parte II/ Cultura. São Paulo: Iluminuras, 2010, pp. 215-226. O Segundo Arco Íris Branco. 
Escrito sobre Jade: Poesia Clássica Chinesa Reimaginada por Haroldo de Campos. São Paulo: Ateliê Editorial, 2009, 2a edição revisada e ampliada. Deus e o Diabo no Fausto de Goethe. São Paulo: Perspectiva, 2005.

. Hagoromo de Zeami. São Paulo: Estação Liberdade, 2003, 2a edição.

. Ideograma. Anagrama. Diagrama: Uma leitura de Fenollosa. In: (org.). Ideograma: lógica, poesia, linguagem. São Paulo: Edusp, 2000. 4ª edição, pp. 23-109.

. Três Versões do Impossível: Wang Wei. In: O Arco Íris Branco. Domínio Chinês. Rio de Janeiro: Imago, 1997, pp. 171-188.

Yugen: Caderno Japonês. In: . Crisantempo. São Paulo: Perspectiva, 1988, pp. 263-289. A quadratura do círculo. In: - A Arte no horizonte do provável. São Paulo: Perspectiva, 1977, 4ª edição, pp. 121-130.

A Arquitextura do Barroco. In: A operação do texto. São Paulo: Perspectiva, 1976, pp. 139-149

O texto-espelho (Poe: $\mathrm{O}$ engenheiro às avessas). In: A operação do texto. São Paulo: Perspectiva, 1976, pp. 23-42.

DANIEL, Claudio. Um Oriente além do Oriente: Releituras de Haroldo de Campos. In: MOTTA, Leda Tenório da. Cén Acima: para um tombeau de Haroldo de Campos. São Paulo: Perspectiva, 2005, pp. 183-192.

DERRIDA, Jacques. Torres de Babel. Belo Horizonte: Editora UFMG, 2002.

LACAN, Jacques. Escritos. Rio de Janeiro: Jorge Zahar Editores, 1998.

LARANJEIRA, Mario. Poética da Tradução. São Paulo: Edusp, 2003.

LOMBARDI, Andrea. Transumanar, transcriar. In: CAMPOS, Haroldo de. Pedra e Lu₹ na poesia de Dante. Rio de Janeiro: Imago, 1998, pp. 9-18.

MALLARMÉ, Stephané. Prefácio a Um lance de dados. In: Mallarmé. Organização e Tradução: CAMPOS, A. et al. São Paulo: Perspectiva, 2002, pp. 23-25.

MATTOS, Gregorio de. Obras Completas [Estabelecimento do texto e notas de José Miguel Wisnik]. São Paulo: Companhia das Letras, 2010.

MEDEIROS, Sérgio. Li-Po e Mao T’se Tung em Português. Resenha. In: Sibila: Revista de Poesia e Cultura. 23, jun.2010. Disponível em: http://sibila.com.br/mapa-da-lingua/ li-po-e-mao-tse-tung-em-portugues/3792. Acesso: 09/01/2013.

NASCIMENTO, Evando. A poética da tradu(ição). In: . (org.) Literatura em perspectiva. Juiz de Fora: UFJF, 2003.

PAZ, Octavio. Traduccion: literatura y literaridad. Tusquets: Barcelona, 1990, $3^{\text {a }}$ edição.

POUND, Ezra. ABC da Literatura, tradução de Augusto de Campos, Haroldo de Campos e Décio Pignatari. São Paulo: Perspectiva, 1970.

SANTAELLA, Lúcia. Transluzir, Transluciferar. A teoria de tradução de Haroldo de Campos. In: MOTTA, Leda Tenório da (org.). Cén Acima: para um tombeau de Haroldo de Campos. São Paulo: Perspectiva, 2005, pp. 221-236. 
SISCAR, Marcos. A desconstrução de Jaques Derrida. In: BONNICI, T.; ZOLIN, L. O. Teoria literária: abordagens históricas e tendências contemporâneas. Maringá: UEM, 2003.

TONETO, Diana Junkes [Bueno] Martha. Haroldo de Campos e a utopia da escritura original. FronteiraZ. São Paulo: PUC, 2011. Disponível em: http://www4.pucsp.br/revis tafronteiraz/numeros_anteriores/n5/download/pdf/Diana_Toneto.pdf Data de acesso: 15/04/2011, republicado em 2012.

Convergências em A Máquina do Mundo Repensada: Poesia e Sincronia em Haroldo de Campos. Tese de Doutoramento. Araraquara: UNESP/ Faculdade de Ciências e Letras, 2008a, 310p.

Entre a invenção e a tradição: história e utopia no projeto poético de Haroldo de Campos. In: Ipotesi. Juiz de Fora: UFJF, v. 12, p. 95-105, 2008 b.

YUN, Jung Im. Do Ideograma ao Fonograma: a travessia haroldiana oriente-ocidente. In: DICK, André (org.). Signâncias: Reflexões sobre Haroldo de Campos. São Paulo: Risco Editorial/ Secretaria da Cultura do Estado de São Paulo/ Poiésis, 2010, p. 242-265.

\title{
Anexos:
}

\author{
leito \\ lúcida lua \\ alumbra \\ uma dúvida: \\ geia na \\ terra escura? \\ cabeça alta \\ olho na \\ lua prata \\ cabeça caída \\ mente na \\ terra antiga
}

(CAMPOS, 2009, p. 59) 

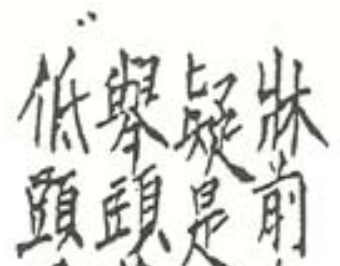

惡望她有

数山上月

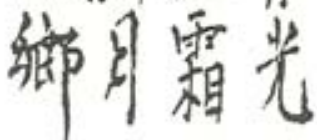

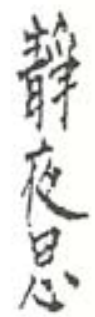

degraus da escada de jade

agora brancos de orvalho

orvalho da noite alta

invade as meias de gaze-

a dama que fez baixar

as persianas de cristal

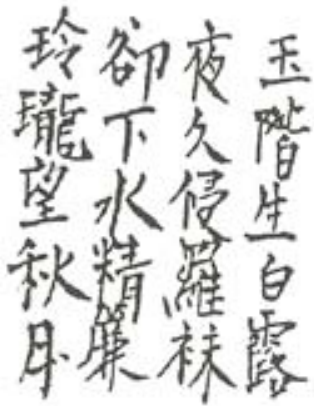

contempla na transparência

a clara lua de outono

(CAMPOS, 2009, p. 63)

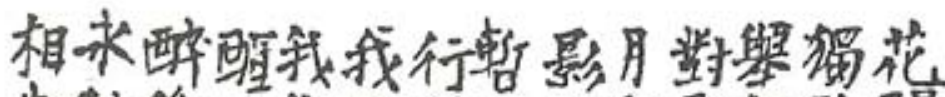

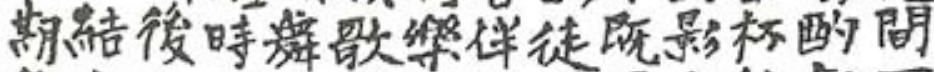

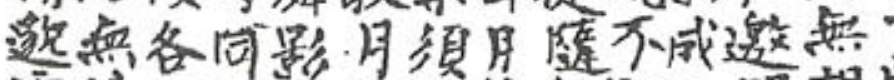
零情分交零徘及將我解三明相喆

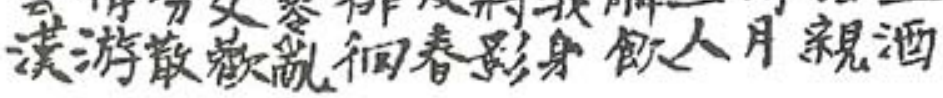




\section{entreflores 花間 uma jarra devinho \\ solitário bebendo sem convivas \\ erguer a copa à lua lunescente 明月 \\ lua e sombra somos três agora}

(mas a lua é sóbria

e em văo

a sombra me arremeda)

uminstante sombra elua celebremos

a alegria volátil primavera!

canto ealua A se evola

danço e a sombra 䒺 se alvoroça

despertos o prazer nos unia

ebrios separamos os caminhos

nôn de água 求結 nunca mais reatáveis?

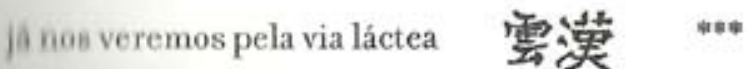

